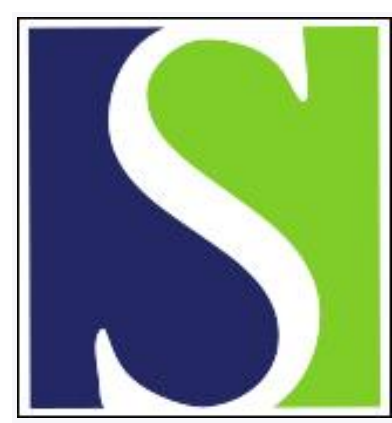

Scand J Work Environ Health 1979;5(1):10-15

https://doi.org/10.5271/sjweh.2671

Issue date: Mar 1979

Lung cancer and residency--a case-referent study on the possible impact of of exposure to radon and its daughters in dwellings.

by Axelson $\mathrm{O}$, Edling $\mathrm{C}$, Kling $\mathrm{H}$

Key terms: case-control; case-referent; case-referent study; daughter in dwelling; dwelling; epidemiologic study; exposure; lung cancer; radon; residency; smoking; urban factor

This article in PubMed: www.ncbi.nlm.nih.gov/pubmed/441704

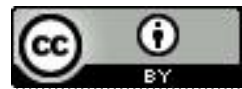




\title{
Lung cancer and residency - A case-referent study on the possible impact of exposure to radon and its daughters in dwellings
}

\author{
by OLAV AXELSON, M.D., CHRISTER EDLING, M.D., \\ and HANS KLING, B.Sc. (Eng.) ${ }^{1}$
}

\begin{abstract}
AXELSON, O., EDLING, C. and KLING, H. Lung cancer and residency - A casereferent study on the possible impact of exposure to radon and its daughters in dwellings. Scand. j. work environ. \& health 5 (1979) 10-15. In view of the wellknown urban-rural difference in lung cancer rates, remaining also after standardization for smoking, it is suggested that low levels of radon and its daughters in dwellings might be of etiologic importance to this disease. To test this hypothesis, a case-referent (case-control) study was undertaken in a rural area; it considered residency in wooden houses (assumed to be associated with low-level exposure to radon and its daughters), "mixed type" houses (medium exposure) and stone houses (high-level exposure) among cases of lung cancer and referents (controls). The results indicate an increased risk of lung cancer among residents in "mixed type" and stone houses. Additional studies are highly desirable to confirm or refute these findings, which, if valid, mean increasing lung cancer hazards caused by a decrease in ventilation in future energy saving unless special measures are undertaken to reduce radon daughters in dwellings.
\end{abstract}

Key words: case-control, case-referent, dwellings, epidemiologic study, lung cancer, radon, smoking, urban factor.

Cigarette smoking is generally accepted as the most important etiologic factor for lung cancer. Occupational exposure may also play a significant role in various industrial subpopulations, but it does not seem to explain fully the well-known urban-rural gradients in lung cancer rates, which are present even after attempts to standardize for smoking.

A recent evaluation of the "urban factor" has focused on air pollution from ben-

\footnotetext{
1 Department of Occupational Medicine, University Hospital, Linköping, Sweden.
}

Reprint requests to: Prof. O. Axelson, Department of Occupational Medicine, University Hospital, S-581 85 Linköping, Sweden. so(a)pyrene (4), but it has also been suggested that a different pattern of cigarette consumption in urban areas might contribute to this disparity (7), although definite estimates are difficult to obtain. It is still more difficult to evaluate precisely other potential risk factors in urban areas, e.g., exposure to many air pollutants like arsenic and other metals or to radon and its daughter products, which are present at low levels in dwellings.

The impact of these various factors has been suggested to be low, including the effect from background alpha-radiation from radon and its daughters (7). In Sweden, however, there has recently been some concern about increasing radon con- 
centrations in dwellings due to decreased ventilation as a result of energy saving measures. Estimates by the Swedish Energy Commission (17) indicate that radon and radon daughters in dwellings could contribute considerably to lung cancer morbidity. This judgement was based on exposure-effect data for lung cancer rates among American uranium miners and other mining populations with exposure to radon and radon daughters, including recent findings of lung cancer mortality among Swedish zinc-lead miners, with a higher lifetime risk than hitherto observed (3). It should be noticed also that the follow-up time of uranium miners is not much more than 23-30 years, nor do there seem to exist any adequately evaluated lifetime studies from the well-known mining communities of Schneeberg and Joachimstal in Europe, in spite of the fact that a high incidence of lung cancer among these miners was already recognized many years ago. Exposure to radon and its daughters might therefore be more hazardous, on a lifetime basis, than earlier recognized, and then even the low levels in dwellings might be of some significance for the etiology of lung cancer.

Measurements of radon levels in dwellings were performed in Sweden already in the 1950 s (8), as well as more recently (16). Concentrations around $1 \mathrm{pCi} / 1$ might occur, but also much higher values have been observed, particularly in houses built from lightweight concrete containing alum shale. Ventilation tends to influence these radon and radon daughter concentrations heavily, and higher levels should therefore be expected in houses with central heating than in those with old-fashioned stove heating that provides a comparatively effective thermal ventilation, at least in the winter when doors and windows are kept closed. Moreover, it is suggested by the measurements of Hultqvist (8) that wooden wall material should produce less radon than various other types of construction material. Rural houses in Sweden are mostly built from wood and have not been equipped with central heating until quite recently, in contrast to most urban houses, which are more commonly built from stone material (brick, concrete of various types, granite, etc.). These differences in the qual- ity of dwellings are of interest in view of the implications for indoor concentrations of radon and daughters and might perhaps help explain the aforementioned urbanrural difference in lung cancer morbidity, which has been observed also in Sweden (5). Moreover, in a rural population there are many outdoor workers, whereas people in urban areas more often work indoors; this factor further contributes to the differences in exposure of this kind.

At the low exposure levels mentioned, nonsmokers might need such a long induction-latency period to develop lung cancer that there is no manifestation within the average life span. This suggestion is supported by the fact that smoking miners seem to develop lung cancer much earlier than their nonsmoking colleagues $(1,3)$. It is not unreasonable, therefore, that a combination of smoking and low-level exposure to radon and daughters in dwellings and indoor workplaces could be of considerable importance to the etiology of lung cancer.

To test the hypothesis that low concentrations of radon and its daughters might contribute to lung cancer development, this case-referent (case-control) study regarding type of residency among cases of lung cancer and referents (controls) was undertaken, i.e., residency in stone houses, wooden houses and other "mixed type" houses was taken as a crude measure of exposure to different levels of radon and daughters. For various reasons, the investigation was restricted to people in typically rural areas, since, for example, urban populations are characterized by great differences in occupations, some of which are perhaps associated with lung cancer hazards. There are also apparent differences between occupations with regard to outdoor and indoor work, and therefore also to exposure to radon and its daughters, and many people living in stone houses and similar buildings might be outdoor workers, whereas residents of wooden houses could well work indoors. Moreover, urban populations tend to be rather mobile; many farmers and farm workers have moved to the towns and cities quite recently and have therefore often changed from more "primitive" and better ventilated wooden houses to more-or-less mod- 
ern houses in urban areas. All these factors tend to counterbalance the differences in actual exposure among urban residents and thereby disqualify urban populations as suitable sources of subjects for a study of this type.

By contrast, rural people tend to work in farming and forestry or related service jobs; most of them are associated with a great deal of outdoor work. Usually they have also lived in the same houses for a considerable period of their lives. Moreover, in many rural areas of Sweden the mixture of houses built from different materials is suitable enough to allow a casereferent study to become efficacious, but at the same time the low lung cancer incidence among rural residents tends to decrease the information of the study by the limited numbers of obtainable cases within a reasonably restricted area of survey (cf. method for exposure classification).

\section{MATERIALS AND METHODS}

The registers of deaths and burials in 28 parishes in the counties of Östergötland and Örebro in southern Sweden were used as the source of subjects for this case-referent study. Some of these parishes also have small towns and suburban areas, but for reasons already discussed the study was strictly confined to the rural population, and all individuals with a street address were therefore excluded. Furthermore, only men and women above 40 years of age were considered; younger persons were not contributing cases and therefore would not provide any information. The study period was $1965-1977$. On the average, the rural source population amounted to 11,300 persons above 40 years of age, as derived from the census of 1970 .

The cases were those subjects who had died from malignant tumors of the lung (ICD 162-163), and referents were those individuals who had entered the register in the three positions before and after each case (i.e., those who had died in a close time-relation to the case) and who remained when cancer diagnoses were excluded. This type of referent selection was applied for reasons of convenience but obviously means a matching procedure, although sets of cases and referents were not maintained in the analyses of the data, since there is little reason to believe that time of death should be any confounding factor in this context (13). However, a stratification was applied to account for possible confounding from age and sex.

If a cancer was mentioned among the death diagnoses, this disease was always taken as the underlying cause of death. It might be added that registers of deaths and burials are of good quality in Sweden and usually contain complete diagnoses as given by the death certificates, which also seem to be reliable (6).

\section{Assessment of exposure}

The addresses given by the registers of deaths and burials were located on largescale economic maps, which permitted the geographic identification of isolated houses. Then, every house was visited by the same investigator and classified into one of three different categories. Wooden houses without a basement (basements are often used for both storage and living) were classified in exposure category 0 , stone houses (all types of stone materials) with a basement were placed in category 2 , and all other houses ("mixed type") were classified in category 1 . The rural wooden house without a basement is fairly characteristic and therefore easy to separate from all other types of houses. Also the typical stone houses were fairly easy to recognize. Some stone houses might appear in category 1 , however, since, particularly, plastered houses were somewhat difficult to classify. Other characteristics of the houses, e.g., type of heating (central heating or stoves) were not accounted for, nor was it possible to attain information about how long the individuals had lived in the house where they spent their last days. However, the crudeness of this categorization of exposure, as well as possible misclassifications of the houses, would apparently tend to wipe out any potential differences in exposure between cases and referents. Smoking habits among cases and referents were possible to establish only for a few individuals through available medical files. 
findings of about $40 \%$ smokers in the rural population of Sweden (5).

It might be mentioned that also those subjects excluded because of having lived in houses with a street address, i.e., the inhabitants of the small towns of some of the parishes and the suburban areas, were similarly studied but showed an overall crude rate ratio of 1.0 . These excluded subjects numbered 225, 39 cases and 187 referents, only 3 cases and 15 referents of both sexes belonging to exposure category 0 . One case and eight referents among the men were referable to category 0 versus 29 cases and 95 referents in exposure categories 1 and 2 combined. Among the women, there were 2 cases and 7 referents in exposure category 0 versus 7 cases and 77 referents in categories 1 and 2 combined, i.e., there were opposite trends in the rate ratio for men and women, but the "nonexposed" subjects were too few to justify a further evaluation of this urban population.

\section{DISCUSSION}

The results of the present study seem to indicate that there might be a relationship between type of residency and lung cancer in rural areas. A social gradient in smoking habits in Sweden is known and is of interest in this context. The fact is that wealthier people smoke somewhat more, but there was no indication in this study, however, of a relation between smoking, income and type of material in the houses in terms of the classification applied in the study, i.e., there was no impression that wealthier people live in stone houses in these parts of Sweden. Moreover, as discussed elsewhere, a rather large difference in smoking between exposed and nonexposed individuals is required to create a rate ratio of 2 or above (2). Eight of the 12 male cases for whom information was available were found to be smokers in this study, i.e., the results are consistent with earlier, well-known findings in studies of lung cancer; therefore, the interpretation is that smoking exerts a role of effect modification (13).
The applied exposure classification is apparently a very crude method with which to estimate exposure to radon and its daughters and tends to make the study conservative. Therefore, although the study is pilot in character, the results nevertheless support the hypothesis that radon and radon daughter exposure in dwellings might be of pertinence to the question of the etiology of lung cancer. Obviously, the urban-rural gradient phenomenon in lung cancer incidence could be easily explained on the basis of exposure to radon and daughters, since rural houses in most countries tend to be more "primitive," having a better natural ventilation and/ or being built of wood to a greater extent than urban dwellings. As has already been pointed out, rural people are often outdoor workers, and their exposure is therefore further decreased. Moreover, the almost fourfold urban-rural gradient among men and 2.5-fold difference among women in Sweden (15) are too large to be explained by different smoking habits (2), nor have urban areas in Sweden been heavily air polluted. This aspect of a fairly small difference in air pollution between urban and rural areas in Scandinavia has in fact been a matter of concern in a World Health Organization evaluation of the impact of air pollution on lung cancer morbidity (18). Moreover, Swedish traffic became intensive quite recently, in the late $1950 \mathrm{~s}$, and there was not enough latency time for a higher urban lung cancer rate to develop already in the 1960s. Nor has there been any heavy air pollution from coal burning.

The results of this preliminary study call for additional research in order to confirm or refute the hypothesis set forth. With increasing efforts to save energy, and therefore decreasing ventilation, the radon and radon daughter concentrations will rise, and, if the findings of this study prove to be valid, a serious lung cancer hazard is threatening the populations in countries with a cold climate. On the other hand, if this hazard can be more definitely assessed, it seems quite reasonable, and indeed easy, to filter indoor air to remove radon daughters in addition to attempting other preventive efforts, such as to decrease smoking. 


\section{ACKNOWLEDGMENT}

We thank Mr. L. Andersson for his technical assistance and Ms. G. Desai for her secretarial help.

\section{REFERENCES}

1. ARCHER, V. E., WAGONER, J. K. and LUNDIN, F. E. Uranium mining and cigarette smoking effects on man. J. occup. med. 15 (1973) 204-211.

2. AXELSON, O. Aspects on confounding in occupational health epidemiology. Scand. j. work environ. \& health 4 (1978) 85-89.

3. AXELSON, O. and SUNDELL, L. Mining, lung cancer and smoking. Scand. j. work environ. \& health 4 (1978) 46-52 (and related data).

4. CARNOW, B. M. The "urban factor" and lung cancer: Cigarette smoking or air pollution? Environ. health perspect. 22 (1978) $17-21$.

5. CEDERLÖF, R., FRIBERG, L., HRUBEC, Z. and LORICH, U. The relationship of smoking and some social covariables to mortality and cancer morbidity. Part 1 \& 2. Department of Environmental Hygiene, Karolinska Institutet, Stockholm 1975. $91 \mathrm{p}$.

6. DE FAIRE, U., FRIBERG, L., LORICH, U. and LUNDMAN, T. A validation of causeof-death certification in 1156 deaths. Acta med. scand. 200 (1976) 223-228.

7. DOLL, R. Atmospheric pollution and lung cancer. Environ. health perspect. 22 (1978) $23-31$.

8. HULTQVIST, B. Studies on naturally occurring ionizing radiations, with special reference to radiation doses in Swedish houses of various types (Kung. Svenska vetenskapsakademiens handlingar, 4:e serien, Band 6, Nr. 3). Almqvist \& Wiksell Boktryckeri AB, Stockholm 1956.

9. MANTEL, N. Chi-square tests with one degree of freedom: Extensions of the Mantel-Haenszel procedure. Am. stat. assoc. $j$. 58 (1963) 690-700.

10. MANTEL, N. and HAENSZEL, W. Statistical aspects of the analysis of the data from retrospective studies of disease. J. natl. cancer inst. 32 (1959) 719-748.

11. MIETTINEN, O. S. Components of the crude risk ratio. Am. j. epidemiol. 96 (1972) $168-172$.

12. MIETTINEN, O. S. Standardization of risk ratio. Am. j. epidemiol. 96 (1972) 383-388.

13. MIETTINEN, O. S. Confounding and effect-modification. Am. j. epidemiol. 100 (1974) $350-353$

14. MIETTINEN, O. S. Estimability and estimation in case-referent studies. Am. j. epidemiol. 103 (1976) 226-235.

15. NATIONAL BOARD OF HEALTH AND WELFARE. The cancer registry: Cancer incidence in Sweden 1959-1965. Stockholm 1971. $197 \mathrm{p}$.

16. SVEDJEMARK, G. A. Radon in dwellings in Sweden. Presented at the 3rd Symposium of Natural Radiation Environment, April 23-28, 1978, Texas.

17. SWEDISH ENERGY COMMISSION. Energy: Health, environmental and security hazards (in Swedish with an English summary). Stockholm 1978. $253 \mathrm{p}$.

18. WORLD HEALTH ORGANIZATION. Health hazards of the human environment. Geneva 1972, p. 29. 